\title{
Currarino-Silverman syndrome: diagnosis and treatment of rare chest wall deformity, a case series
}

\author{
Andrei I. Gritsiuta ${ }^{1,2} \wedge$, Alexander Bracken ${ }^{1}$, Karisa Beebe $^{1}$, Alexei A. Pechetov ${ }^{2 \wedge}$ \\ ${ }^{1}$ Department of Surgical Services, University of Pittsburgh Medical Center, Pittsburgh, PA, USA; ${ }^{2}$ Department of Thoracic Surgery, Vishnevsky \\ National Medical Research Center of Surgery, Moscow, Russia \\ Contributions: (I) Conception and design: All authors; (II) Administrative support: AA Pechetov; (III) Provision of study materials or patients: AI \\ Gritsiuta, AA Pechetov; (IV) Collection and assembly of data: All authors; (V) Data analysis and interpretation: All authors; (VI) Manuscript writing: \\ All authors; (VII) Final approval of manuscript: All authors. \\ Correspondence to: Andrei I. Gritsiuta, MD, PhD. Department of Surgical Services, University of Pittsburgh Medical Center, 3600 Forbes Avenue, \\ Pittsburgh, PA 15213, USA. Email: gritsiutaai@upmc.edu.
}

Background: Currarino-Silverman (CS) syndrome is an extremely rare congenital deformity of the anterior chest wall. The syndrome is often combined with congenital heart defects and spinal abnormalities. As of currently, there is a lack of definite description in the literature about this type of pectus deformity. Typically, patients do not require surgical intervention for medical reasons, and the correction is usually only for cosmetic purposes. The purpose of this study was to demonstrate surgical intervention for CS syndrome at a tertiary care facility, and to summarize the available literature.

Methods: Patients with CS syndrome were retrospectively reviewed from a period of June 2012 to August 2019. An extensive literature search for "Currarino-Silverman syndrome," "pouter pigeon chest," "chondromanubrial deformity," "type 2 pectus carinatum" and "pectus arcuatum" was performed.

Results: Four clinical cases of CS syndrome are presented, two of which were symptomatic and corrected. The procedure of choice was the modified Ravitch-type thoracoplasty with double osteotomy and implantation of support plates.

Conclusions: There is no clear definition of CS syndrome in the literature. Correct and uniform classification plays a crucial role in the surgical treatment of this pathology. Due to the extreme rarity of the disease, challenging deformity, and variable anatomy of the fused sternum, there are no clear guidelines in treatment approaches. The correction is mostly pursued only for cosmetic results, and the best surgical option for CS syndrome remains the relatively aggressive Ravitch-type procedure with multi-level wedge osteotomy.

Keywords: Diagnosis and treatment of Currarino-Silverman syndrome; pouter pigeon chest; chondromanubrial deformity; pectus arcuatum; case series

Submitted Dec 08, 2020. Accepted for publication Mar 25, 2021.

doi: $10.21037 /$ jtd-20-3472

View this article at: http://dx.doi.org/10.21037/jtd-20-3472

\section{Introduction}

Pectus carinatum (PC) and pectus excavatum (PE) are the most common congenital anterior chest wall deformities which present at an early age and manifest during adolescence. $\mathrm{PC}$ is seen less frequently than $\mathrm{PE}$, comprising about $5-15 \%$ of patients with pectus abnormalities and occurs in about 1:1,000-1:10,000 of all live births with a male predominance $(4: 1)(1,2)$. Some data indicate that milder forms of $\mathrm{PC}$ are more frequent, with even greater

^ ORCID: Andrei I. Gritsiuta, 0000-0003-2265-9992; Alexei A. Pechetov, 0000-0002-1823-4396. 


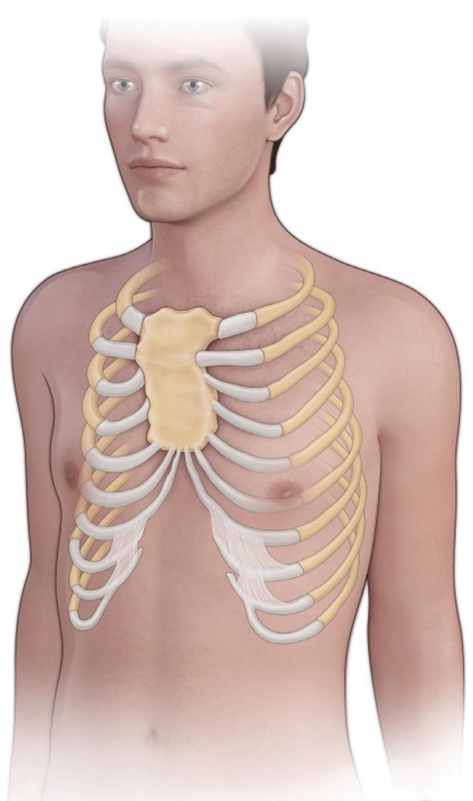

Figure 1 Anatomical representation of Currarino-Silverman syndrome: short, broad, fused sternum with prominent outward protrusion; the xiphoid process is absent; deformed, fused and elongated costal cartilages formed abnormal sharp angle.

prevalence than PE and ratio of 2:1 $(3,4)$. The etiology of PC is not fully understood, however, the generally accepted theory is that the deformity is secondary to an excessive growth of costal cartilage secondary to genetic factors, which results in a sternal deformity without pathology in the sternum itself (5).

PC includes variable subtypes with two principal groups: chondrogladiolar (type 1) and chondromanubrial (type 2). Most intriguing is the chondromanubrial type, which was first described by Guido Currarino and Frederic Silverman in 1958, since the etiology and features are different (6). Currarino-Silverman (CS) syndrome is a rare (less than $1 \%$ of PC), complex chest wall anomaly caused by premature obliteration of the ossification centers in the sternum resulting in a high PC (type 2) deformity (7). Degenerative changes in hyaline cartilages, atypical fibrils, reduced number of chondrocytes, and thin periosteum are observed microscopically (8). A unique appearance, characterized by a short, z-shaped, solid sternum with prominent outward protrusion and bilateral deformity of the second to fifth costal cartilages that form an acute intercostal angle allow this syndrome to be considered as a distinct entity (5). The xiphoid process is directed forward or is altogether absent
(Figure 1).

The theory of a congenital etiology by gene downregulation is predominant (9-11). A family history of chest wall deformity is observed in approximately one-fourth of patients (1). An abnormality of the differentiation of the anterior segment mesenchymal cells at the time of cardiogenesis may result in defects of the endocardial cushion, sternum, and aortic arch derivatives. Abnormal migration of mesenchymal cardiac precursors to the endothelial heart tube is also caused by the abnormal genes (12). CS syndrome is often associated with spinal deformities (kyphosis, scoliosis and kyphoscoliosis), congenital heart defects, and was described as a component of Turner's and Noonan's syndromes $(8,13)$.

Frequent confusion of CS syndrome with PE deformity is still an issue since one-third of patients present with concomitant mild to moderate depression of the lower third of the sternum $(8,13,14)$. Uniform classification is a basis for surgical treatment as well as an assessment of its short and long-term results. This article will review the diagnosis and treatment of four consecutive patients with CS syndrome.

We present the following article in accordance with the AME Case Series reporting checklist (available at http:// dx.doi.org/10.21037/jtd-20-3472).

\section{Methods}

The medical records of four consecutive adult patients with CS syndrome from a single tertiary academic hospital from June 2012 to August 2019 were retrospectively reviewed. Patient demographics and characteristics are provided in Table 1. All four patients were young females with a mean age of 21 years (range, 18-24 years). Echocardiography revealed various cardiac pathology in three patients: mitral and tricuspid regurgitation, mitral valve prolapse, and ventricular septal defect (VSD). In all four patients the sternum length did not exceed $10 \mathrm{~cm}$. Two of the four patients were asymptomatic and refused surgical correction for what they viewed as purely cosmetic purposes (Figure 2). One of the two was misdiagnosed with PE type of deformity and corrected with Nuss procedure three years prior with no significant clinical benefit. In this case, subsequent simple bar removal was performed under general anesthesia with no further intervention planned. In two other cases (Figures 3,4), the procedure of choice was a modified Ravitch-type thoracoplasty with double osteotomy. Follow up periods were from 23 to 34 months without recurrence. As this was a retrospective review, approval from a local ethics committee 
Table 1 Summary of patients with Currarino-Silverman syndrome

\begin{tabular}{lcccccccc}
\hline Case & Age & Height $(\mathrm{cm})$ & Weight $(\mathrm{kg})$ & $\mathrm{BMI}\left(\mathrm{kg} / \mathrm{m}^{2}\right)$ & Sternum length $(\mathrm{mm})$ & Sternum angle $\left({ }^{\circ}\right)$ & Spine & Echocardiogram \\
\hline 1 & 18 & 160 & 61 & 23.83 & 9 & 115 & Kyphosis & MR + TR \\
2 & 24 & 168 & 47 & 16.65 & 10 & 110 & None & MVP 3 mm + VSD 3 mm \\
3 & 18 & 162 & 48 & 18.29 & 8.5 & 135 & Kyphosis & Negative \\
4 & 24 & 177 & 52 & 17 & 10 & 122 & Kyphoscoliosis & MVP $5 \mathrm{~mm}$ \\
\hline
\end{tabular}

MR, mitral regurgitation; MVP, mitral valve prolapse; TR, tricuspid regurgitation; VSD, ventricular septal defect.
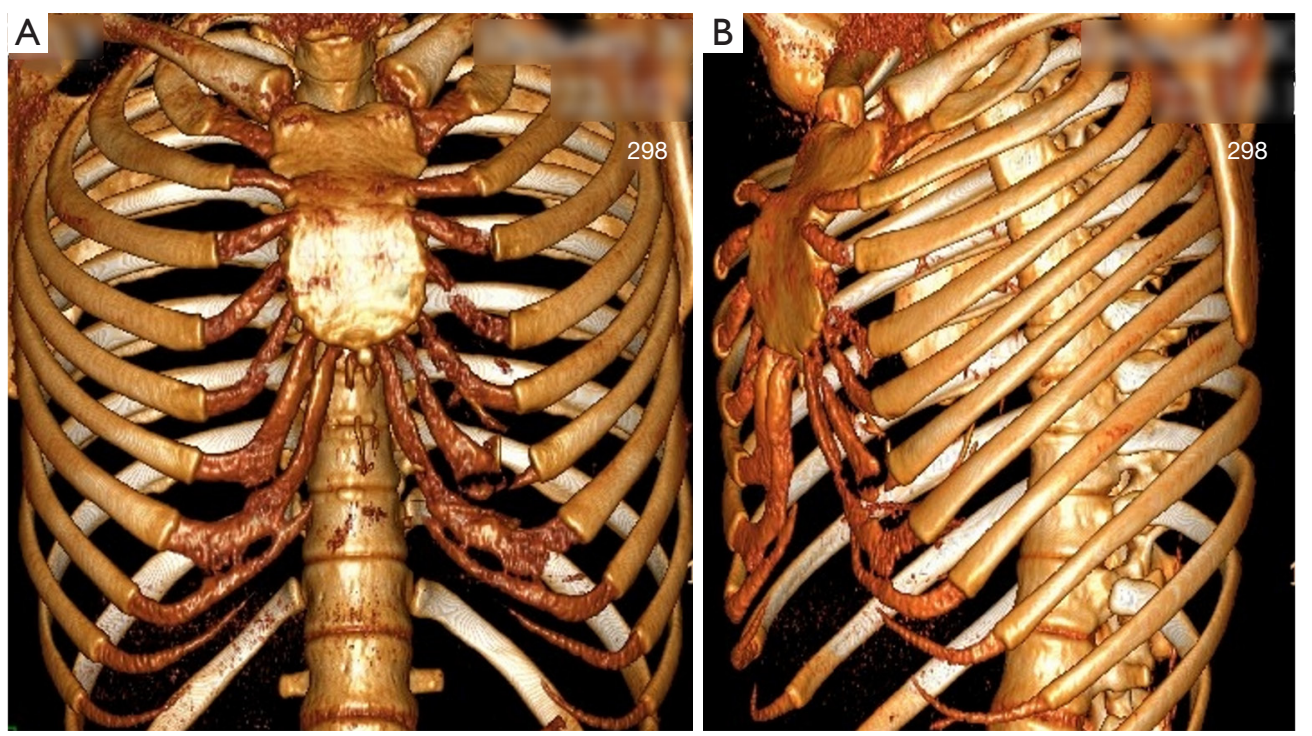

Figure 2 Chest CT with 3D reconstruction (A) frontal and (B) lateral views of the 18-year-old female, showing completely fused broad 8.5 -cm-long sternum with marked anterior protrusion at obliterated manubriosternal joint (135-degree angle) and no depression in the lower third.

was not required. All procedures performed in studies involving human participants were in accordance with the ethical standards of the institutional research committee and with the Helsinki Declaration (as revised in 2013). Written informed consent was obtained from all patients.

\section{Literature review}

A systematic analysis of electronic databases was performed including the MEDLINE, PubMed, CINAHL, EMBASE and OVID using medical subject headings "Currarino-Silverman syndrome," "pouter pigeon chest," "chondromanubrial deformity," "type 2 pectus carinatum" and "pectus arcuatum." A total of 22 appropriate fulltext case reports and case series in English language were identified through database and reference searches from
1952 to 2019 (Table 2). Articles describing PE deformities were not included in this database search. Much of the identified literature is limited by relatively short term follow up, likely secondary to the younger patient population and the lack of symptoms both pre- and post-operatively.

\section{Results}

Described below are the case presentations and clinical courses of two patients with CS syndrome. The other two patients described in this paper are not included as they refused surgical intervention for cosmesis.

\section{Patient 1}

An 18-year-old female with an inborn chest wall 

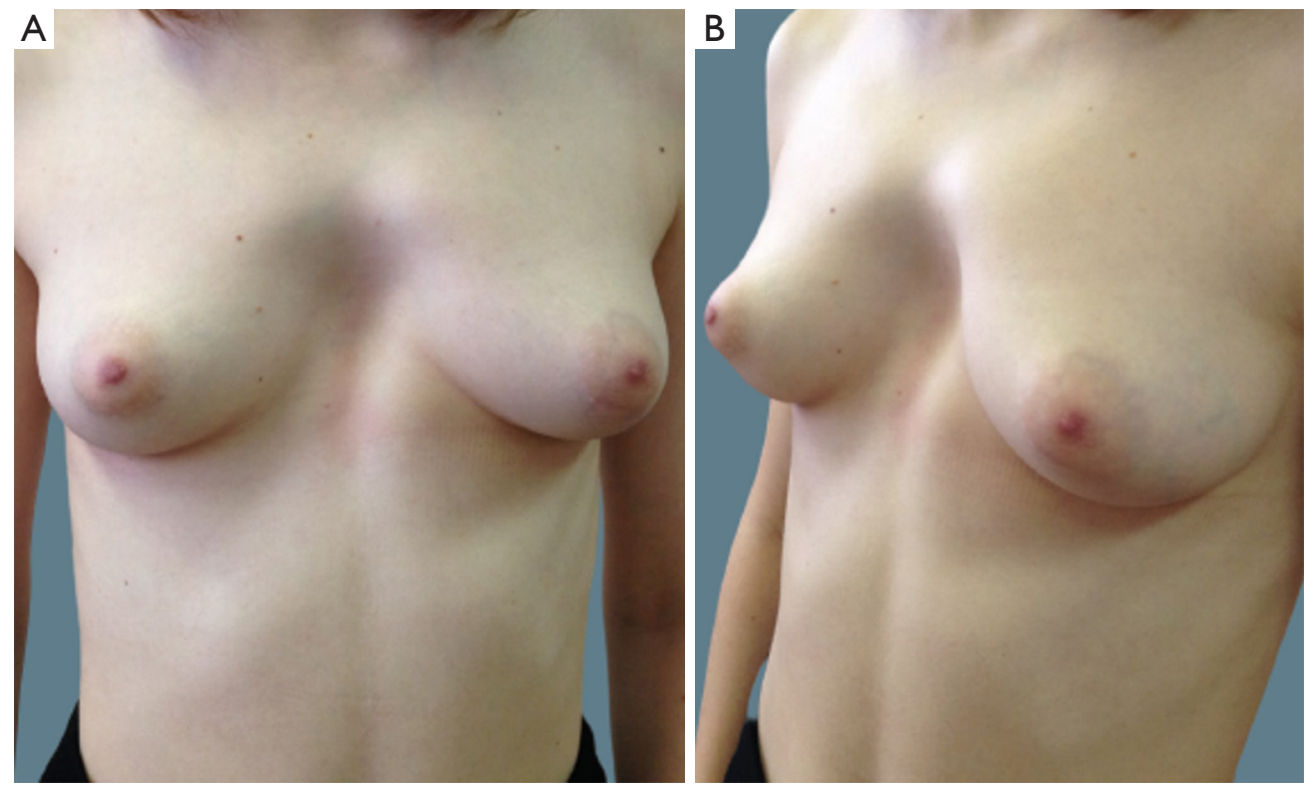

Figure 3 Clinical presentation of an 18-year-old female patient with Currarino-Silverman syndrome. (A) Frontal view. (B) Lateral view.
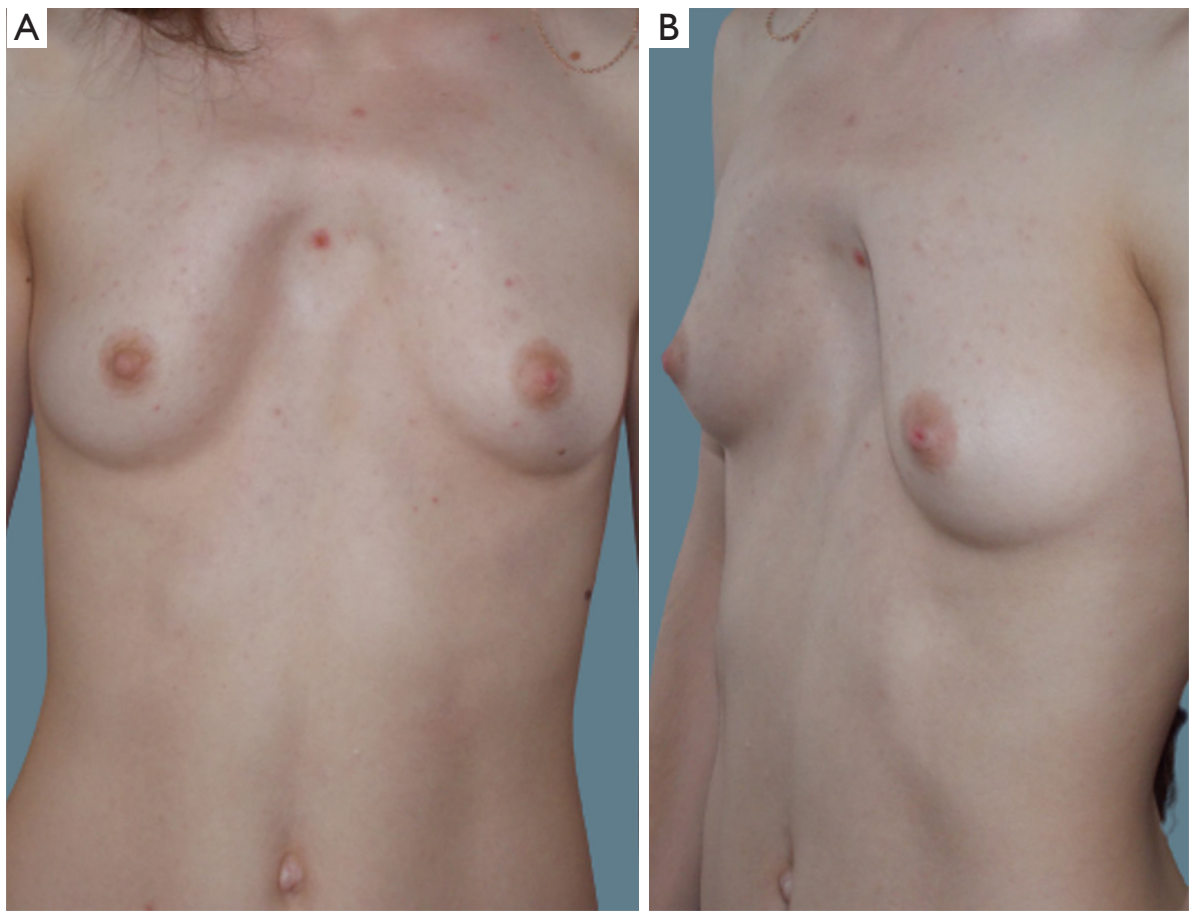

Figure 4 Clinical presentation of a 24-year-old female with Currarino-Silverman syndrome. (A) Frontal view. (B) Lateral view.

deformity progressing from the age of 16 presented with complaints of dyspnea and nagging sternal pain (Figure 3). A chest magnetic resonance imaging scan revealed a chondromanubrial deformity with a dorsal-open angle of 115 degrees and a sternum body length of $9 \mathrm{~cm}$. Surgical correction was performed through a transverse submammary skin incision in respect to the lines of Langer. Musculocutaneous flaps were dissected bilaterally up to the 
Table 2 Currarino-Silverman syndrome in the literature

\begin{tabular}{|c|c|c|c|c|c|c|c|}
\hline Author & Year & $\begin{array}{c}\mathrm{N} \text { of } \\
\text { patients }\end{array}$ & $\begin{array}{c}\mathrm{N} \text { of } \\
\text { osteotomies }\end{array}$ & $\begin{array}{l}\mathrm{N} \text { of cartilages } \\
\text { resected }\end{array}$ & Bar & $\begin{array}{l}\text { STRATOS } \\
\text { system }\end{array}$ & Cardiac defects \\
\hline Ravitch et al. (15) & 1952 & 1 & 2 & 5 & - & - & Arrhythmia \\
\hline Lester et al. (14) & 1953 & 1 & 1 & 5 & - & - & $\mathrm{N} / \mathrm{A}$ \\
\hline Monnet et al. (16) & 1956 & 1 & & No surgery & & & TGA+VSD+PAPVC \\
\hline Brunner et al. (17) & 1961 & 1 & & No surgery & & & TOF \\
\hline Andrén et al. (18 ) & 1961 & 7 & & No surgery & & & $\begin{array}{l}\text { 1, ASD+VSD; } 1 \text {, TOF; } \\
\text { 1, ASD+PVS; } 1 \text {, PVS; } 1 \text {, } \\
\text { HLHS+PD A }\end{array}$ \\
\hline Shamberger et al. (7) & 1988 & 5 & 1 & 6 & - & - & No \\
\hline Chidambaram et al. (13) & 1992 & 5 & & No surgery & & & $\begin{array}{l}\text { 1, PMV+MS+MR; } 1, \mathrm{MR} ; 2 \\
\mathrm{MVP}+\mathrm{MR} ; 1, \mathrm{CoA}\end{array}$ \\
\hline Mehta et al. (20) & 1996 & 1 & & No surgery & & & 1, CoA+PMV \\
\hline Fonkalsrud et al. $(21,22)$ & 2001, 2004 & 18 & $2-3$ & 6 & + & - & $N / A$ \\
\hline Brichon et al. (23) & 2010 & 1 & 3 & 5 & - & + & $\mathrm{N} / \mathrm{A}$ \\
\hline Wurtz et al. (24) & 2012 & 5 & 1 & $3-4$ & + & - & $\mathrm{N} / \mathrm{A}$ \\
\hline Emil et al. (4) & 2018 & $\mathrm{~N} / \mathrm{A}$ & 1 & - & + & - & $\mathrm{N} / \mathrm{A}$ \\
\hline Leng et al. (30) & 2019 & 6 & 1 & 3 & + & - & $\mathrm{N} / \mathrm{A}$ \\
\hline
\end{tabular}

ARSA, aberrant right subclavian artery; ASD, atrial septal defect; CoA, coarctation of the aorta; DAA, double aortic arch; HLHS, hypoplastic left heart syndrome; MR, mitral regurgitation; MS, mitral stenosis; MVP, mitral valve prolapse; PAPVC, partial anomalous pulmonary venous connection; PDA, patent ductus arteriosus; PMV, parachute mitral valve; PVS, pulmonary valve stenosis; TGA, transposition of the great arteries; TOF, tetralogy of Fallot; VSD, ventricular septal defect.

level of the sternal notch with detachment of the pectoralis musculature and retracted laterally. Subperichondrial resections of the 2nd-5th costal cartilages were completed bilaterally with preservation of perichondrium to avoid chest wall weakness postoperatively. Careful attention was also given to the growth centers of the sterno-chondral and costo-chondral junctions to avoid development of a restrictive deformity. In the projection of maximal protrusion of the sternal body, at the level of the third rib and second intercostal space, a two-level wedge-shaped transverse osteotomy was subsequently performed using an oscillating saw preserving the integrity of the posterior lamina. Remodeling of the sternum was performed by applying caudal pressure at the top of the deformity and anterior traction at the sternal body. Osteosynthesis of the lower sternum osteotomy site was then accomplished using 

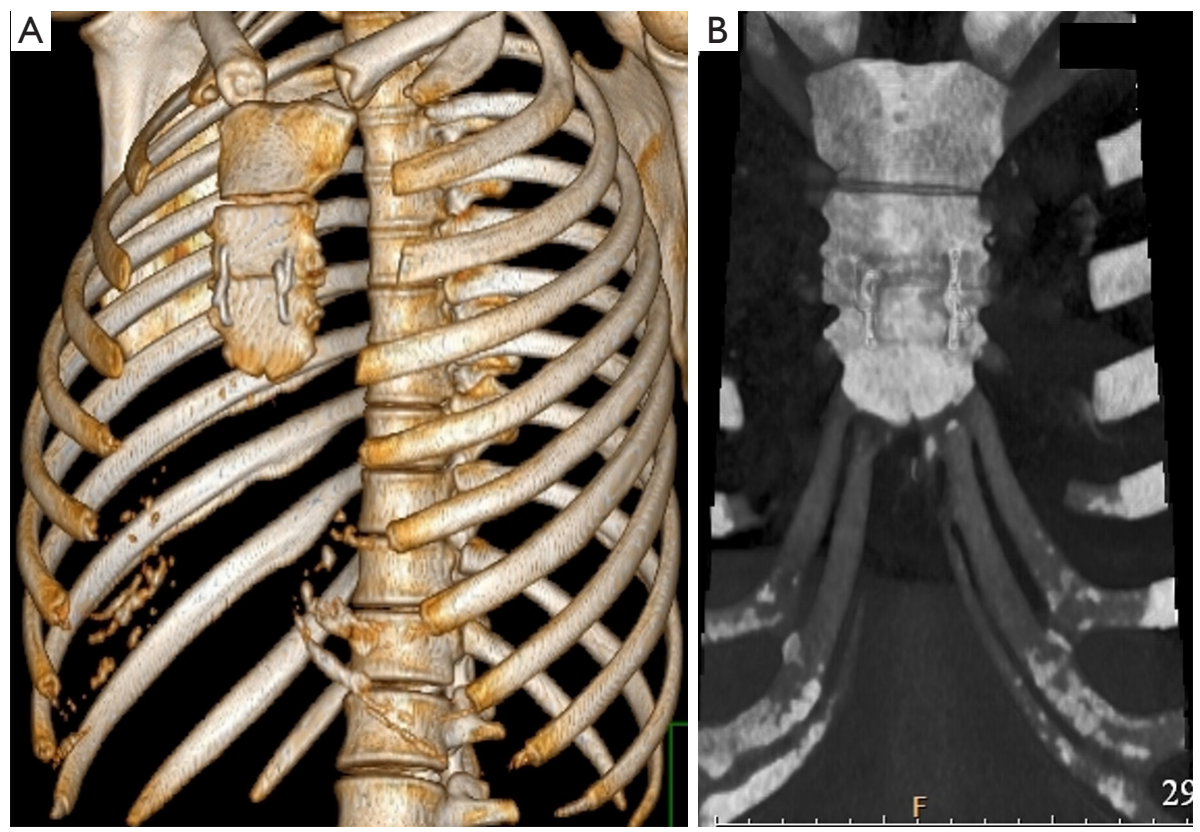

Figure 5 An 18-year-old female patient with Currarino-Silverman syndrome, (A) lateral view of 3D reconstruction (B) chest CT 6 months postoperatively.

two parallel 316L stainless steel surgical monofilament wires (Ethicon, USA) (Figure 5). The edges of the divided pectoralis musculature were approximated with interrupted suture followed by closure of the skin flaps. The postoperative period was unremarkable with satisfactory correction of the deformity. The patient was discharged from the hospital on postoperative day 5 . The follow-up period was 23 months, with subjective resolution of her symptoms and no recurrence of the deformity noted.

\section{Patient 2}

This patient is a 24-year-old female with a chest wall deformity first noted at age 4 and progression to the age of 13 (Figure 4). Her only complaint was exertional dyspnea. Imaging revealed a fused, broad, $10 \mathrm{~cm}$ long sternum and marked anterior protrusion at the obliterated manubriosternal joint with a 110-degree angle. Repair was performed via a submammary skin incision and subperichondrial resection of bilateral $2 \mathrm{nd}-7$ th costal cartilages in similar fashion to that as described above under Patient 1. Complete transverse osteotomy at the level of the upper third of the sternum was followed by osteosynthesis with two parallel low profile titanium plates (Matrix Rib Fixation System, $1.5 \mathrm{~mm}$ thickness, $2.9 \mathrm{~mm}$ diameter of screws; DePuy Synthes CMF, West Chester, PA, USA) bicortically fixed with eight self-locking screws. The postoperative period was unremarkable and the patient was discharged on postoperative day 7. The follow-up period was 34 months, with subjective resolution of her exertional dyspnea and no recurrence of the deformity noted (Figure 6).

\section{Discussion}

There is no clear definition of CS syndrome in the literature. In 1949, Brodkin recognized two types of PC deformity: lower chondrogladiolar and upper chondromanubrial prominences (31). In 1953, Lester used terms "oblique" and "arcuate" for lower and upper forms respectively (14). The first case of an entirely fused and angulated forward sternum in conjunction with cyanotic congenital heart disease was described in French by Monnet et al. in 1956 (16). According to the original paper of Currarino and Silverman (6), this rare developmental anomaly is characterized by prominent sternal angulation with decrease in length as a result of congenital complete non-segmentation, or premature synostosis of the sternum. Authors noted clinical similarity of this deformity with arcuate pigeon breast, a type of PC of Lester's classification.

In 2006, Acastello (32) classified chest wall deformities 

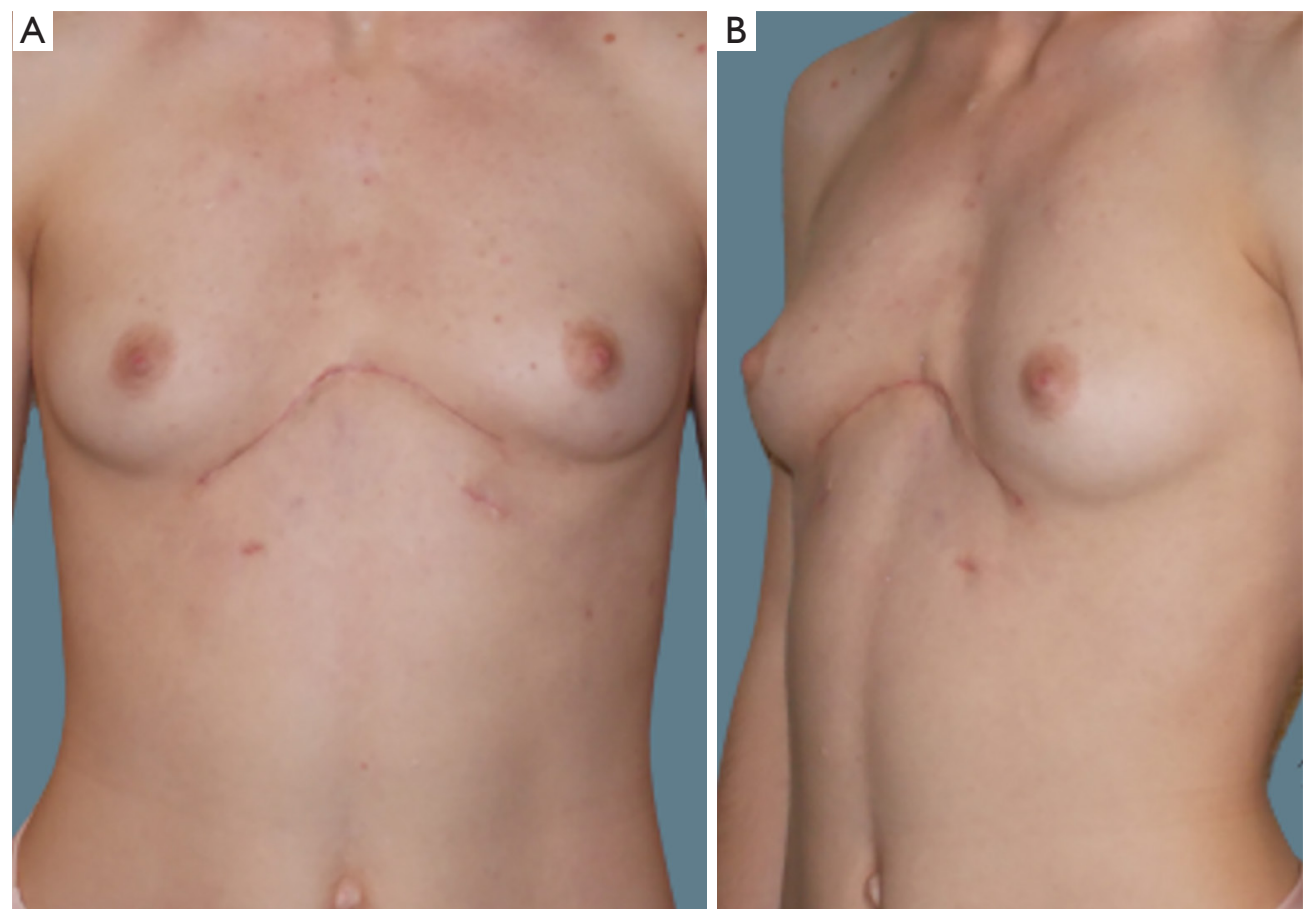

Figure 6 A 24-year-old female with Currarino-Silverman syndrome, one month postoperatively. (A) Frontal view. (B) Lateral view.

based on the site of the defect's origin (type 1: cartilaginous, type 2: costal, type 3: chondrocostal, type 4: sternal, type 5: clavicle-scapular) and attributed CS syndrome to the cartilaginous type 2 (superior) PC. Further, Torre et al. (3) distinguished superior PC into two different types: the "true" type 2 (superior or chondromanubrial) PC had normal sternal length without depression in the lower third due to cartilage anomaly. The authors emphasized the presence of a short, thick, S-shaped sternum with inferior $\mathrm{PE}$ as CS syndrome resulting in a high symmetric PC chest wall deformity and attributed it to sternal anomalies according to Acastello's classification. It is worth noting that the authors described combined PC and PE malformation as type 1 (cartilaginous) PE. Wurtz et al. (24) classified chest wall deformities according to the cartilage involvement and related pectus arcuatum (PA) in two different types: "2nd to 4th or 5th" type or "high" forms of PA, and "2nd to 7 th" type or PA associated with a lower depression. The latter is the most consistent with Torre's description of CS syndrome. Fokin et al. (5) and Robicsek et al. (33) considered CS syndrome as a separate "transitional" group under the term "Pouter pigeon breast." Authors subclassified this deformity according to the different degrees of the angle of Louis.
On the other hand, some authors consider CS syndrome as a variant of PE. Cartoski et al. (34) classified this deformity as a "steer horn" type of PE based only on clinically observed pectus depression within a diverse cohort of surgical patients. However, the authors pointed that it also may be a variant of the chondromanubrial deformity of PC and should be treated with the Ravitch procedure. Kelly et al. (35) retrospectively reviewed records of $300 \mathrm{PE}$ cases, and described CS as a rare subtype of $\mathrm{PE}$ which occurred in $1 \%$ of patients, more specifically as a mixed PE and PC type.

Indeed, CS syndrome can be easily mistaken with PE since both deformities appear in almost similar fashion, but surgical approaches are very different. A distinctive feature of a PE deformity is the beginning of the sternal depression at the angle of Louis that becomes progressively deeper toward the xiphoid process with distorted, elongated cartilages (25). The angle of Louis must be less than 110 degrees to be considered a true depression (5). Thus, confusion about classification is still an actual issue. Terms "Currarino-Silverman syndrome," "pouter pigeon chest," "chondromanubrial deformity," "type 2 pectus carinatum" and "pectus arcuatum" are used, at times, interchangeably. Correct and uniform classification plays a crucial role in the surgical treatment of this pathology. Most patients with CS 
syndrome are asymptomatic, therefore surgical correction is optional and different opinions exist about the ideal age for surgical correction. Late puberty or adulthood was indicated as a preferred age for correction since cartilages resection will be performed when rib growth ends $(7,24,28)$. It is important to keep in mind the potential for thoracic dystrophy should cartilage resection be carried out at too young an age, or too extensively. That being said, other studies reported the preferable age of 5- to 7-year-old, or early adolescence $(8,21)$.

When symptoms occur, they are often confined to shortness of breath, pain or tenderness at the site of protrusion, decreased endurance, or palpitations. Concomitant asthma and frequent respiratory infections are also described $(14,21)$. A strong correlation of inborn cardiac pathology with CS syndrome has been reported, such as VSD, patent ductus arteriosus, atrial septal defect (ASD), VSD, tetralogy of Fallot, transposition of the great arteries, and coarctation of aorta (Table 2). Interestingly, Chidambaram et al. (13) emphasized that 4 out of 5 patients with CS have cardiac defects in their series and all four were female as in our study. Thus, cardiovascular evaluation should by performed in all patients with CS syndrome. Chest CT with 3D reconstruction, or MRI in children given altered tissue density and radiation concern, is the best preoperative imaging for evaluation of CS patients. It allows for a differential diagnosis with other pectus deformities, determination of exact angles of the costal cartilages to the sternum, and enhanced surgical planning.

The first successful surgical correction of CS syndrome described by Ravitch in 1952 (15), consisted of elevation of the pectoralis major muscle followed by removing short segments of the deformed costal cartilage and performing two transverse osteotomies at the area of the maximal protrusion point in the sternal body. Lester in the same year developed a more radical technique of subperiosteal resection of the protruding portion of the sternum (14). In 1960, Ravitch (10) summarized his experience of surgical treatment of PC and highlighted three main steps: subperichondrial cartilage resection, transverse sternotomy preserving the posterior bone plate and periosteum, and osteosynthesis by fixation of the corrected shape of the chest wall. One patient from this monumental paper presented with typical CS syndrome.

Robicsek described his modification, which was first reported in 1963 (19,33), depending on the CS syndrome type: type A (moderate depression of the sternal body dominated by the protrusion of the manubrium and two adjacent cartilages) and type B (significant depression).
In type A, subperichondrial resection of the protruding cartilages and transverse osteotomy with resection of the anterior portion of the prominent manubrium was performed. In type $B$, an additional transverse-wedge sternotomy at the upper level of the depression followed by Marlex mesh placement was completed.

Lam et al. (9) resected $2 \mathrm{~cm}$ of sternum at the point of greatest prominence with an additional two transverse osteotomies above and below the resection. A similar technique with three osteotomies and resection of the curved anterior angle of the deformed sternum was described by Brichon et al. (23) in a 24-year-old patient with severe "pouter pigeon chest." The osteosynthesis with a titanium system (STRATOS - Strasbourg Thoracic Osteosynthesis System) placed in front of the sternum was performed instead of a bar placement for chest wall stabilization. Kara et al. (26) in their report used two STRATOS implants introduced through the retrosternal space.

Shamberger et al. (7) reported their surgical experience of 179 patients with PC, five $(2.7 \%)$ of which had CS syndrome. In this case series, a broad, high wedge-shaped osteotomy centered at the point of maximum protrusion was performed and the second osteotomy was not required. The same technique was demonstrated by Welch et al. (11) in two $(7.6 \%)$ patients with CS syndrome.

In 2001, Fonkalsrud et al. (21) published their 30-year experience of surgical treatment of PC. Chondromanubrial type was diagnosed in $12(13 \%)$ of 90 patients. According to the authors, in $50 \%$ of cases, multiple (second and third) osteotomies were required. Perichondrial sheaths were preserved during cartilage resection. Each of the costal cartilages was reattached to the sternum and ribs. Authors placed the Adkins strut posterior to the lower tip of the sternum to correct sternal depression, as well as to eliminate postoperative flail chest and paradoxical respiration. The authors emphasized the importance of bar in providing chest stability during costal cartilage regeneration and decreasing the chance of recurrence. Later, Fonkalsrud et al. (22) extended their experience with six new patients with CS syndrome defects that were corrected using the same technique. Bar placement was described by several other surgeons $(4,9,24)$.

Kuzmichev et al. (28) used parallel vertical low profile titanium plates for the sternal osteosynthesis. The authors indicated that their method is completely extrapleural and does not need the second operation for plate removal. Leng et al. (30) reported total surgical experience of 7 patients with CS syndrome. Authors also used vertical 
titanium plates along with novel computer-aided design and templates for precise osteotomy angle with a reported excellent cosmetic outcome. Additionally, the Nuss procedure was performed in two patients.

In comparison to $\mathrm{PE}$, a number of less invasive techniques have been developed for the correction of PC, including the Abramson procedure and its modifications, along with nonsurgical options such as observation, orthotic bracing, and dynamic compression $(2,36)$. However, due to the extreme rarity of the disease, challenging deformity and variable anatomy of fused sternum, there are no clear guidelines in the treatment approaches. This unique growth pattern contributes to almost universal failure of conservative treatment options like the vacuum bell or a compressive orthosis.

This review was of a single institution with limitations inherent of a retrospective study. This review is without a comparison analysis, since only one surgical technique was performed. Case numbers for comparison are difficult to ascertain given the rarity of the disease process. The asymptomatic nature of the deformity also leads to a degree of hesitancy regarding surgical correction, again limiting data.

In conclusion, our retrospective results suggest that the surgical correction of CS syndrome be pursued at this time only with the goal of cosmetic improvement, and although patients reported subjective improvement in dyspnea related symptoms, significant objective clinical benefit was not appreciated in the patients studied. The best surgical option remains the relatively aggressive Ravitch-type procedure with multi-level wedge osteotomy $(3,23,26,36)$, allowing for the achievement of a satisfactory outcome, including a high satisfaction rate in this group of patients. Given the rarity of the deformity, it's surgical correction should be completed by a multidisciplinary team, including thoracic reconstructive surgeons with experience in pectus deformities. Future study could include more extensive pre-operative workup and data collection to compare with postoperative values, to ascertain whether a clinical benefit may also accompany the cosmetic result achieved by surgical intervention.

\section{Acknowledgments}

Funding: None.

\section{Footnote}

Reporting Checklist: The authors have completed the AME
Case Series reporting checklist. Available at http://dx.doi. org/10.21037/jtd-20-3472

Data Sharing Statement: Available at http://dx.doi. org/10.21037/jtd-20-3472

Peer Review File: Available at http://dx.doi.org/10.21037/jtd20-3472

Conflicts of Interest: All authors have completed the ICMJE uniform disclosure form (available at http://dx.doi. org/10.21037/jtd-20-3472). The authors have no conflicts of interest to declare.

Ethical Statement: The authors are accountable for all aspects of the work in ensuring that questions related to the accuracy or integrity of any part of the work are appropriately investigated and resolved. As this was a retrospective review, approval from a local ethics committee was not required. All procedures performed in studies involving human participants were in accordance with the ethical standards of the institutional research committee and with the Helsinki Declaration (as revised in 2013). Written informed consent was obtained from all patients.

Open Access Statement: This is an Open Access article distributed in accordance with the Creative Commons Attribution-NonCommercial-NoDerivs 4.0 International License (CC BY-NC-ND 4.0), which permits the noncommercial replication and distribution of the article with the strict proviso that no changes or edits are made and the original work is properly cited (including links to both the formal publication through the relevant DOI and the license). See: https://creativecommons.org/licenses/by-nc-nd/4.0/.

\section{References}

1. Shamberger RC, Welch KJ. Surgical correction of pectus carinatum. J Pediatr Surg 1987;22:48-53.

2. Muntean A, Stoica I, Saxena A. Pigeon chest: comparative analysis of surgical techniques in minimal access repair of pectus carinatum (MARPC). World J Pediatr 2018;14:18-25.

3. Torre M, Rapuzzi G, Jasonni V, et al. Chest Wall Deformities: An Overview on Classification and Surgical Options. InTech 2012;117-36.

4. Emil S. Current Options for the Treatment of Pectus Carinatum: When to Brace and When to Operate? Eur J 
Pediatr Surg 2018;28:347-54.

5. Fokin AA, Steuerwald NM, Ahrens WA, et al. Anatomical, Histologic, and Genetic Characteristics of Congenital Chest Wall Deformities. Semin Thorac Cardiovasc Surg 2009;21:44-57.

6. Currarino G, Silverman FN. Premature obliteration of the sternal sutures and pigeon-breast deformity. Radiology 1958;70:532-40.

7. Shamberger RC, Welch KJ. Surgical correction of chondromanubrial deformity (Currarino Silverman syndrome). J Pediatr Surg 1988;23:319-22.

8. Fokin AA. Pouter pigeon breast. Chest Surg Clin N Am 2000;10:377.

9. Lam CR, Taber RE. Surgical Treatment of Pectus Carinatum. Arch Surg 1971;103:191-4.

10. Ravitch MM. Operative Correction of Pectus Carinatum (Pigeon Breast). Ann Surg 1960;151:705-14.

11. Welch KJ, Vos A. Surgical correction of pectus carinatum (pigeon breast). J Pediatr Surg 1973;8:659-67.

12. Gabrielsen TO, Ladyman GH. Early closure of the sternal sutures and congenital heart disease. Am J Roentgenol Radium Ther Nucl Med 1963;89:975-83.

13. Chidambaram B, Mehta AV. Currarino-Silverman Syndrome (Pectus Carinatum Type 2 Deformity) and Mitral Valve Disease. Chest 1992;102:780-2.

14. Lester CW. Pigeon breast (pectus carinatum) and other protrusion deformities of the chest of developmental origin. Ann Surg 1953;137:482-9.

15. Ravitch MM. Unusual sternal deformity with cardiac symptoms operative correction. J Thorac Surg 1952;23:138.

16. Monnet P, Gravier J, Gauthier J, et al. Combination of partial vascular transposition (aortic dextroversion) with abnormal venous return and a thoracic malformation caused by premature ossification of the sternum. Pediatrie 1956;11:95.

17. Brunner S. Premature Synostosis in the Sternum (Silverman's Disease). Acta Pædiatrica 1961;50:288-90.

18. Andrén L, Hall P. Diminished segmentation or premature ossification of the sternum in congenital heart disease. $\mathrm{Br}$ Heart J 1961;23:140-2.

19. Robicsek F, Daugherty HK, Mullen DC, et al. Technical Considerations in the Surgical Management of Pectus Excavatum and Carinatum. Ann Thorac Surg 1974;18:549-64.

20. Mehta AV. Currarino-Silverman syndrome and congenital heart disease. Tex Heart Inst J 1996;23:69.
21. Fonkalsrud EW, Beanes S. Surgical Management of Pectus Carinatum: 30 Years' Experience. World J Surg 2001;25:898-903.

22. Fonkalsrud EW, Anselmo DM. Less extensive techniques for repair of pectus carinatum: The undertreated chest deformity. J Am Coll Surg 2004;198:898-905.

23. Brichon PY, Wihlm JM. Correction of a Severe Pouter Pigeon Breast by Triple Sternal Osteotomy With a Novel Titanium Rib Bridge Fixation. Ann Thorac Surg 2010;90:e97-9.

24. Wurtz A, Rousse N, Benhamed L, et al. Simplified open repair for anterior chest wall deformities. Analysis of results in 205 patients. Orthop Traumatol Surg Res 2012;98:319-26.

25. Allwyn Joshua S, Shetty L, Pare V, et al. Chondromanubrial deformity and bifid rib, rare variations seen in pectus carinatum: a radiological finding. Surg Radiol Anat 2013;35:443-7.

26. Kara M, Gundogdu AG, Kadioglu SZ, et al. The use of sternal wedge osteotomy in pectus surgery: when is it necessary? Asian Cardiovasc Thorac Ann 2016;24:658-62.

27. Kim SY, Park S, Kim ER, et al. A Case of Successful Surgical Repair for Pectus Arcuatum Using Chondrosternoplasty. Korean J Thorac Cardiovasc Surg 2016;49:214-7.

28. Kuzmichev V, Ershova K, Adamyan R. Surgical correction of pectus arcuatum. J Vis Surg 2016;2:55.

29. Akkas Y, Kocer B, Peri NG. A new technique for mixedtype pectus carinatum: modified Onen method. Asian Cardiovasc Thorac Ann 2016;24:227-30.

30. Leng S, Bici K, Facchini F, et al. Customized Cutting Template to Assist Sternotomy in Pectus Arcuatum. Ann Thorac Surg 2019;107:1253-8.

31. Brodkin HA. Congenital chondrosternal prominence (pigeon breast) a new interpretation. Pediatrics 1949;3:286.

32. Acastello E. Patologias de la pared toracica en pediatria. Buenos Aires: Editorial El Ateneo; 2006.

33. Robicsek F, Watts LT. Pectus Carinatum. Thorac Surg Clin 2010;20:563-74.

34. Cartoski MJ, Nuss D, Goretsky MJ, et al. Classification of the dysmorphology of pectus excavatum. J Pediatr Surg 2006;41:1573-81.

35. Kelly RE, Quinn A, Varela P, et al. Dysmorphology of Chest Wall Deformities: Frequency Distribution of 
Subtypes of Typical Pectus Excavatum and Rare Subtypes. Arch Bronconeumol 2013;49:196-200.

36. Bostanci K, Ozalper MH, Eldem B, et al. Quality of life

Cite this article as: Gritsiuta AI, Bracken A, Beebe K, Pechetov AA. Currarino-Silverman syndrome: diagnosis and treatment of rare chest wall deformity, a case series. J Thorac Dis 2021;13(5):2968-2978. doi: 10.21037/jtd-20-3472 of patients who have undergone the minimally invasive repair of pectus carinatum. Eur J Cardiothorac Surg 2013;43:122-6. 